EXTENDED REPORT

\title{
Trends in hip and knee joint replacement: socioeconomic inequalities and projections of need
}

\author{
T Dixon, M Shaw, S Ebrahim, P Dieppe
}

Ann Rheum Dis 2004;63:825-830. doi: 10.1136/ard.2003.012724

See end of article for authors' affiliations

........................

Correspondence to: Professor P Dieppe, Department of Social Medicine, Canynge Hall, Whiteladies Rd, Bristol BS8 2PR, UK; P.Dieppe@ bristol.ac.uk

Accepted

14 September 2003

\begin{abstract}
Objectives: To examine trends in primary and revision joint (hip and knee) replacement in England between 1991 and 2000.

Methods: Analysis of hospital episodes statistics between 1 April 1991 and 30 March 2001 for total hip replacement (THR) and total knee replacement (TKR). Descriptive statistics and regression modelling were used to summarise patients' demographic and clinical characteristics and to explore variations in joint surgery rates by age, sex, and deprivation.

Results: Between 1991 and 2000, the incidence of primary THR increased by 18\%, while the incidence of revision THR more than doubled. The incidence of primary TKR doubled, with revision TKR increasing by $300 \%$. Over the 10 year period, the proportion of THR episodes that involved revision operations rose from $8 \%$ to $20 \%$. Substantial variations in operation rates by socioeconomic status were seen, with the most deprived fifth of the population experiencing significantly lower rates. Projections estimate that primary THR numbers could rise by up to $22 \%$ by the year 2010 , with primary TKR numbers rising by up to $63 \%$.

Conclusions: Provision of joint replacement surgery in English NHS hospitals has increased substantially over the past decade. Revision operations in particular have increased markedly. The growth in primary operations has mostly occurred among those aged 60 years and over; rates among young people have changed very little. There is a significant deprivation based gradient in rates. If current trends continue there would be almost 47000 primary hip and 54000 primary knee operations annually by 2010 .
\end{abstract}

O steoarthritis is a major cause of pain and disability, particularly in older people. ${ }^{1-3}$ Total hip replacement and total knee replacement are recognised as costeffective treatments for osteoarthritis of the hip and knee, reducing pain, increasing mobility, and improving the quality of life. ${ }^{4-6}$ Fractured neck of femur, for which over $90 \%$ of patients admitted to hospital are aged 60 or over, may also result in joint replacement surgery. As the population ages, it has been estimated that the number of hip replacements provided in the United Kingdom will have to increase by at least $40 \%$ by 2026 in order to satisfy need. ${ }^{7}$

Joint replacement rates are known to be higher among women and to peak in older age groups (65-84 years). Social disparity has been reported for both primary and revision operations, with lower rates among those of lower social class or socioeconomic status, despite equal or greater indications of need. ${ }^{8-10}$

Increases in rates of hip and knee replacement over the 1990s have been reported in Scandinavia, ${ }^{11-15}$ Australia, ${ }^{16}$ and the USA. ${ }^{17}$ However, there are no national data currently published for England. The aim of this report was to examine trends in the provision of total hip and knee replacement in England between 1991 and 2000, and to investigate demographic characteristics. Specifically, we examined variation (according to age, sex, and area level deprivation) in primary and revision operations over time; and provide projections of numbers and rates for the year 2010, taking into account expected changes in population age structure.

\section{METHODS}

Hospital episode statistics (HES) for England were used. The HES database (held by the Department of Health) holds information on patients who are admitted to NHS hospitals in England, either as day cases or as ordinary admissions. Each record in the database relates to one "finished consultant episode." This is the period of time an individual spends under the care of one NHS consultant. Private hospital procedures are excluded from HES as there is no requirement for such hospitals to provide routine data (although some private patients are treated in NHS hospitals). It has been estimated that around $20 \%$ of hip and knee joint replacement procedures in England are carried out in private institutions. ${ }^{18}$

The information held in the HES database includes the age and sex of the patient, area of usual residence, reason for admittance (diagnosis) to hospital, and procedure undertaken. Information is now available for financial years April 1989 to March 2002. Further information on HES is available from the Department of Health website at http://www.doh. gov.uk/hes/.

Episodes involving total joint replacement surgery were identified as those with any of the OPSC4 codes W37, W38, W39 (hip joint) or W40, W41 or W42 (knee joint) recorded in any of the 4 procedure fields. Revision operations were identified as episodes having any of the above procedure codes plus a primary diagnosis indicating complications due to internal prostheses (ICD-9 codes 996.4, 996.6, or 996.7 and ICD-10 codes T84 or T85).

Age standardised procedure rates were calculated using five year age groups with the English mid-year population of 1996 as the reference. The Townsend index of deprivation, ${ }^{19}$ derived from 1991 census data and reported at ward level (a small administrative geographical unit of 5500 people on avarage), was used as an indicator of relative socioeconomic disadvantage in the area of residence. Factors independently associated with a higher rate of joint replacement procedures were identified using negative binomial regression.

Abbreviations: HES, hospital episode statistics; THR, total hip replacement; TKR, total knee replacement 
Two methods were used to calculate projected joint replacement numbers in 2010:

- Extension of simple linear regression lines through the age specific primary and revision rates for each sex, and application of these projected age specific rates to the projected population numbers in 2010 .

- Application of the most recent sex and age specific rates (that is, for the year 2000) to population projections for the year 2010 .

The first method assumes that rates will continue to increase at the same pace as they have over the 1991-2000 period, and that the population at risk for joint replacement will change. The second method assumes that the current rates will remain stable and that change in the numbers at risk will be the only cause of change in the number of operations. As the number of joint replacement procedures undertaken in 2010 will depend on various factors-including the rate of uptake of procedures, the number of people requiring the operations, the resources available, and the cost-the actual number of joint replacement procedures in NHS hospitals in 2010 is likely to fall somewhere in between the projections given by the two methods.

\section{RESULTS}

\section{Hip replacement}

Both primary and revision operations were more common among women than men, though the trends followed similar patterns (fig 1, table 1). Primary operations generally increased over the study period, although there was a slight dip during 1996 and 1997. Age standardised primary procedure rates (for men and women aggregated) increased by $18 \%$ (95\% confidence interval (CI), $16 \%$ to $21 \%$ ), from 65.5 per 100000 in 1991 ( 31211 episodes) to 77.6 per 100000 in 2000 (38 425 episodes). Revision operations started from a much lower absolute level (3678 episodes, 7.8 per 100000 in 1991) but rose continually over the time period to reach 19.8 per 100000 in 2000 (9507 episodes-a 154\% increase (95\% CI, $135 \%$ to $161 \%$ ), although the rate of increase slowed from 1998. On average, the rise in total volume of procedures over the period equates to around 600 additional primary operations and 700 additional revision operations a year. The more rapid increase in revision operations compared with primary operations is demonstrated by the increased proportion of hip replacement episodes involving revision operations, which rose from one in 12 in 1991 to one in five in 2000 .

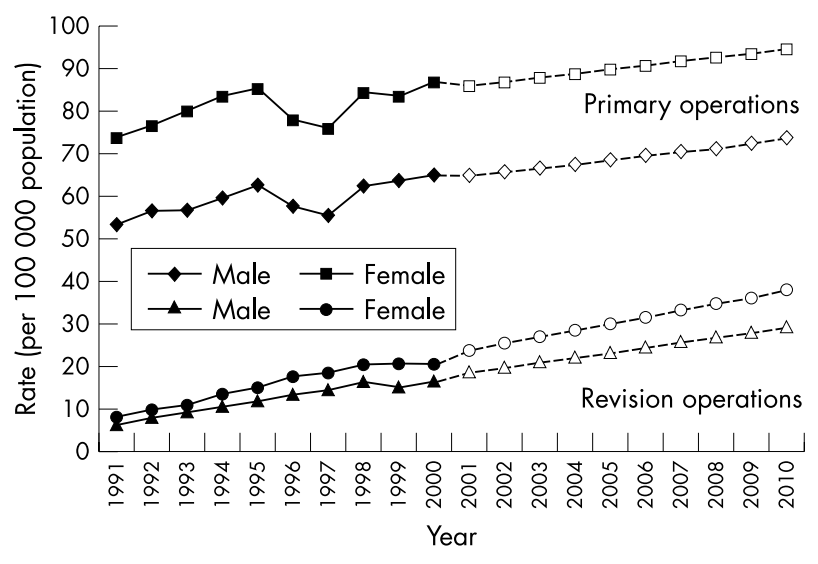

Figure 1 Trends in primary and revision hip replacement rates, 19912000 , and projections to 2010 , by sex. Rates are age standardised to the England mid-year population of 1996. Source: HES, Department of Health.
Rates for both primary and revision operations were highest in the older age groups. The mean age of patients undergoing primary operations was 68.6 years, while the mean age of revision was 71.8 years. Age specific rates for primary operations in younger people were relatively low and were similar in men and women; these changed little between 1991 and 2000. From age 50 to 54 years the female rate was higher than the male rate, reaching a maximum difference of 178 episodes per 100000 (62\% difference) in the 75 to 79 year age group in 2000. For those aged 60 years and over, rates increased over the period in all age groups with the exception of 75-79 year old men. Dramatic increases in revision operations were seen in the oldest age groups, with the rates among those aged 85 and over rising by $477 \%$ among men and $278 \%$ among women. However, this accounted for only a small absolute number of episodes: 300 men and 995 women of this age in 2000 (data available on request).

Primary hip replacement rates in 2000 were significantly lower in the most deprived fifth of the population than in the remaining four fifths. A gradient of increasing rates with decreasing deprivation could be seen from the most to the least deprived in both sexes (fig 2). There was no significant difference in rates between the most advantaged two fifths for either men or women. Revision hip replacements (for 1998 to 2000 combined) also showed a deprivation gradient, with rates rising significantly between each fifth from the most to the least deprived.

Negative binomial regression showed that the characteristics most associated with having a primary hip replacement were being female, aged 65 to 69 years, and being from the least deprived areas. Being female, aged 75 to 79 , and being from the least deprived areas were most highly associated with having a revision operation at the hip (data not shown).

\section{Knee replacement}

Episodes of primary knee replacement were more common among women than men, although the difference between the sexes was smaller than for hip replacement (fig 3, table 2). The total number of knee replacement episodes more than doubled over the 1990s, with an average increase of 1730 primary operations and 266 revision operations a year. Again, the trend was similar between the sexes, with no significant difference in the rate of increase, and the same dip in primary operation rates during 1996 and 1997 as was seen for hip replacement. The proportion of revision operations tripled over the period, from one in 33 to one in 11 , and there was no difference in revision rates between the sexes.

Between 1991 and 2000, the rate of primary knee replacement episodes more than doubled in the age group 55 to 59 and above in men, and in several age groups in women. Rates in the youngest age groups remained steady. In 2000, the 75-79 year age group showed the highest rate of episodes for both sexes (384 per 100000 men, 430 per 100000 women). Rates of revision operations increased quite dramatically, although in many cases these started from a very low value. Mean patient ages were 70.6 years for primary operations and 69.6 years for revisions.

Both primary and revision knee replacement rates were significantly lower in the most deprived fifth of the population than in the remaining four fifths (fig 4).

Negative binomial regression showed that the characteristics most associated with having a primary knee replacement were being female, being aged 70 to 74 years, and not being from the most deprived fifth of the population (data not shown). Being female, aged 70 to 79 , and not from the most deprived fifth were most associated with having a revision operation at the knee. 


\begin{tabular}{|c|c|c|c|c|c|c|c|c|}
\hline \multirow[b]{2}{*}{ Age group (years) } & \multicolumn{2}{|c|}{ Men, primary } & \multicolumn{2}{|c|}{ Women, primary } & \multicolumn{2}{|c|}{ Men, revision } & \multicolumn{2}{|c|}{ Women, revision } \\
\hline & $\mathrm{N}$ & Rate & $\mathrm{N}$ & Rate & $\mathrm{N}$ & Rate & $\mathrm{N}$ & Rate \\
\hline$<35$ & 167 & 1.5 & 208 & 1.9 & 41 & 0.4 & 53 & 0.5 \\
\hline 35 to 39 & 164 & 8.6 & 168 & 8.6 & 29 & 1.5 & 52 & 2.7 \\
\hline 40 to 44 & 257 & 15.3 & 259 & 15.2 & 46 & 2.7 & 91 & 5.3 \\
\hline 45 to 49 & 412 & 26.8 & 434 & 27.7 & 74 & 4.8 & 97 & 6.2 \\
\hline 50 to 54 & 857 & 51.3 & 1075 & 63.4 & 155 & 9.3 & 203 & 12.0 \\
\hline 55 to 59 & 1355 & 101.1 & 1690 & 123.7 & 247 & 18.4 & 283 & 20.7 \\
\hline 60 to 64 & 2241 & 189.6 & 2895 & 236.1 & 420 & 35.5 & 474 & 38.7 \\
\hline 65 to 69 & 2969 & 287.8 & 3815 & 339.3 & 590 & 57.2 & 662 & 58.9 \\
\hline 70 to 74 & 2479 & 281.2 & 4466 & 420.3 & 589 & 66.8 & 931 & 87.6 \\
\hline 75 to 79 & 1987 & 286.3 & 4566 & 464.7 & 583 & 84.0 & 1192 & 121.3 \\
\hline 80 to 84 & 1114 & 291.2 & 2735 & 412.2 & 423 & 110.6 & 977 & 147.2 \\
\hline $85+$ & 519 & 198.9 & 1593 & 231.7 & 300 & 114.9 & 995 & 144.7 \\
\hline Total $^{*}$ & 14521 & 65.5 & 23904 & 87.1 & 3,497 & 16.6 & 6010 & 21.0 \\
\hline
\end{tabular}

${ }^{*}$ Total rates have been age standardised to the 1996 England population.

\section{Projections}

Number of operations

For primary hip replacements the estimates based on year 2000 rates (method B) suggest a 7\% (women) to 15\% (men) increase in the number of episodes by 2010, to a total of 42134 episodes, while the estimates based on projected rates (method A) suggest a total of 46772 episodes-an increase of $17 \%$ in women and $30 \%$ in men (table 3 ). For hip revisions, method B estimates a 6-15\% increase to a total of 10354 , while method A suggests that numbers in 2010 will be around double the numbers in 2000, at 18564 episodes.

Estimates of numbers of primary knee replacement episodes in 2010 based on year 2000 rates show an increase of $6 \%$ to $14 \%$ from 2000 (35 894 in total), while the estimates based on projected rates suggest a much larger increase of $53 \%$ to $77 \%$ at a total of 53712 episodes. Knee revision numbers based on year 2000 rates again show a $6 \%$ to $14 \%$ increase from 2000 (total 3297), with projected rate estimates suggesting the number of knee revisions will more than double to 6400 by 2010 .

\section{Age standardised rates}

Linear projections of the trends from 1991 to 2000 suggest that age standardised rates of primary hip replacement may rise to 94 per 100000 in women and 74 per 100000 in men by 2010 (fig 1). Similar projection of revision rates could see 38 revisions per 100000 women and 29 per 100000 men at

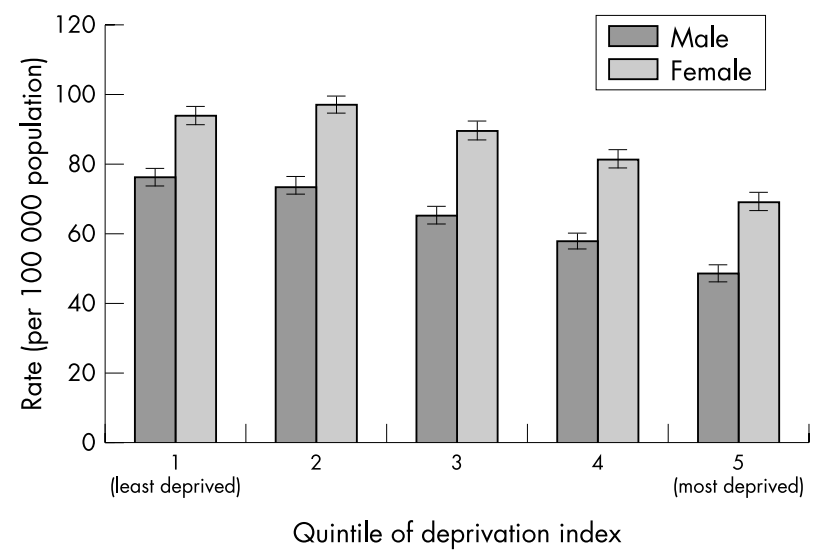

Figure 2 Age standardised rates (and 95\% confidence intervals) of primary hip replacements by quintile of deprivation index, 2000. Rates are age standardised to the England mid-year population of 1996. Source: HES, Department of Health. this date. However, if the levelling of revision rates seen in the most recent years continues, rates may rise very little between 2000 and 2010.

Projecting the trends in knee replacement rates, by 2010 there could be 102 primary operations per 100000 women and 97 per 100000 men (fig 3). The rate of increase of revision operations was smaller but would lead to 11 and 12 operations per 100000 women and men, respectively. The rapid rate of increase in knee replacement procedures during the 1990s suggests that knee replacement rates could rise above hip replacement rates by 2002 for men and by 2007 for women.

\section{DISCUSSION}

Rates of primary and revision joint replacement in English NHS hospitals increased between 1991 and 2000. In keeping with the epidemiology of osteoarthritis and fractured neck of femur, $^{20}$ the rates of primary operations were higher in women and older people (aged 65 to 79). However, the number of operations carried out in those aged 55 to 64 and 80 years and over rose significantly over the 10 year period, with a growing proportion of operations being done in the over 85s. As anaesthetic and surgical techniques and outcomes improve, more very elderly people may be considered suitable for surgery, further increasing the need for provision of hip and knee replacement surgery in this age group.

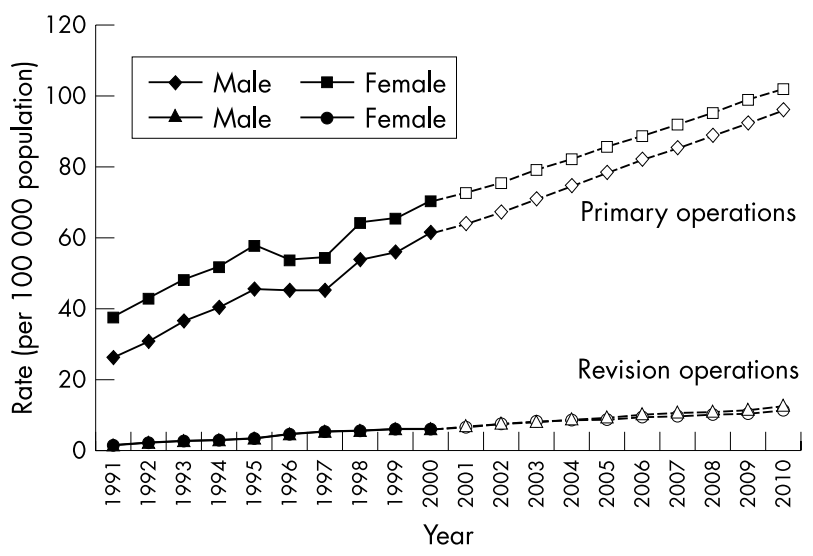

Figure 3 Trends in primary and revision knee replacement rates, 1991-2000, and projections to 2010 , by sex. Rates are age standardised to the England mid-year population of 1996. Source: HES, Department of Health. 


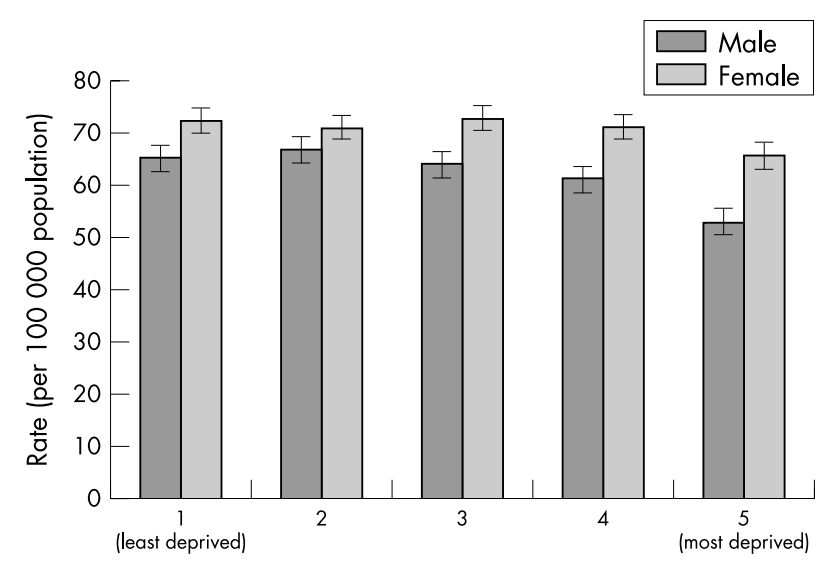

Quintile of deprivation index

Figure 4 Age standardised rates (and 95\% confidence intervals) of primary knee replacements by quintile of deprivation index, 2000. Rates are age standardised to the England mid-year population of 1996. Source: HES, Department of Health.

Rates of knee replacement increased at a faster pace than hip replacements, leading to projections that knee replacements will become more common than hip replacements by 2010 if the observed trends continue. Indeed among men aged 70 to 84 this is already the case. In Australia ${ }^{16}$ and the $\mathrm{USA}^{17}$ there are more knee replacements than hip replacements; conversely in Sweden, hip replacements are much more common. ${ }^{1121}$ Without data on the incidence, prevalence, and severity of arthritis at the hip and knee and fractured neck of femur, and information regarding clinicians' and patients' attitudes to joint replacement surgery, it is unclear whether these differences reflect variations in need or in clinical practice between countries. They may also indicate differing amounts of resources available to provide joint replacement surgery.

The proportion of hip and knee replacement revision operations in 2000 is similar to that seen in other countries. One in five hip replacement episodes in the NHS in 2000 was a revision, compared with one in four operations in Finland ${ }^{15}$ and one in six in Denmark ${ }^{13}$ and the USA. ${ }^{17}$ Also in 2000 revisions made up one of every 11 knee replacements in the NHS, the same proportion as in the USA ${ }^{17}$ but slightly higher than in Sweden (one in 13). ${ }^{12}$

In view of the current government and NHS focus on reducing health inequalities, ${ }^{22}$ the deprivation gradient in operation rates highlights an area that warrants further investigation. It is possible that this gradient reflects real variation in need or patient consent to surgery. However, some studies have suggested that need is greater among the most deprived groups, and that education and income are unrelated to willingness to undergo joint replacement surgery. ${ }^{10}$ If so, this would imply inequity in the provision of joint replacement surgery. Further, as patients in private hospitals are more likely to be from the less deprived sectors of the population, the true nature of these inequities may be even more severe.

Assuming equal need and equal desire for surgery, to remove the deprivation based inequity in primary hip operations within the NHS in 2000, the rates would need to rise by around $50 \%$ in the most deprived fifth, by $25 \%$ in next most deprived fifth, and by $12 \%$ in the middle fifth. This is an overall increase of $14 \%$-5300 extra operations a year, nearly nine times the current annual rate of increase. The inequity in primary knee operations is less, but rates would need to increase by over $15 \%$ in the most deprived group to achieve equity-over 900 extra operations (3\% of total). These increases would lead to even higher projected numbers of procedures in 2010.

It is not possible using these data to determine the reason for the different effects of deprivation on hip and knee replacement rates. It may be that there is a difference in the relation between deprivation and osteoarthritis of the hip and knee, with osteoarthritis of the knee showing a stronger gradient; the same degree of inequity in the provision of hip and knee operations would then result in the observed patterns. However, until data on the prevalence of hip and knee osteoarthritis are available by degree of deprivation this can be only speculation.

Projections of rising demand for joint replacement surgery have implications for service provision, planning, and costs. An increase in revision operations would have an adverse impact on resources. Revision operations are estimated to cost up to twice as much as primary operations, and to involve a longer length of stay. ${ }^{23}$ An increase in the number of revision operations would therefore not only increase costs but decrease the number of beds available and potentially reduce the overall number of operations that could be done.

Waiting list reports show that current provision of joint replacement surgery does not meet need; while waiting lists are decreasing there are still thousands of people waiting for surgery, with many waiting more than six months. Should provision not keep pace with the projected increase in the need for surgery, waiting times and numbers could rise,

Table 2 Number and rate (per 100000 population) of episodes involving primary and revision total knee replacement, by age group and sex, 2000. Source: HES, Department of Health

\begin{tabular}{|c|c|c|c|c|c|c|c|c|}
\hline \multirow[b]{2}{*}{ Age group (years) } & \multicolumn{2}{|c|}{ Men, primary } & \multicolumn{2}{|c|}{ Women, primary } & \multicolumn{2}{|c|}{ Men, revision } & \multicolumn{2}{|c|}{ Women, revision } \\
\hline & $\mathrm{N}$ & Rate & $\mathbf{N}$ & Rate & $\mathbf{N}$ & Rate & $\mathbf{N}$ & Rate \\
\hline$<35$ & 31 & 0.3 & 51 & 0.5 & * & * & * & * \\
\hline 35 to 39 & 21 & 1.1 & 31 & 1.6 & * & * & * & * \\
\hline 40 to 44 & 60 & 3.6 & 77 & 4.5 & 15 & 0.9 & 14 & 0.8 \\
\hline 45 to 49 & 145 & 9.4 & 179 & 11.4 & 31 & 2.0 & 34 & 2.2 \\
\hline 50 to 54 & 355 & 21.2 & 594 & 35.0 & 48 & 2.9 & 51 & 3.0 \\
\hline 55 to 59 & 925 & 69.0 & 1096 & 80.2 & 94 & 7.0 & 117 & 8.6 \\
\hline 60 to 64 & 2009 & 169.9 & 2130 & 173.7 & 213 & 18.0 & 193 & 15.7 \\
\hline 65 to 69 & 2627 & 254.7 & 3267 & 290.6 & 293 & 28.4 & 242 & 21.5 \\
\hline 70 to 74 & 3129 & 354.9 & 4436 & 417.5 & 268 & 30.4 & 326 & 30.7 \\
\hline 75 to 79 & 2666 & 384.1 & 4224 & 429.9 & 264 & 38.0 & 331 & 33.7 \\
\hline 80 to 84 & 1159 & 303.0 & 2302 & 346.9 & 111 & 29.0 & 171 & 25.8 \\
\hline $85+$ & 403 & 154.4 & 1026 & 149.3 & 39 & 14.9 & 115 & 16.7 \\
\hline Total† & 13530 & 62.1 & 19413 & 70.7 & 1387 & 6.3 & 1609 & 5.9 \\
\hline
\end{tabular}

*Detail suppressed; fewer than 10 episodes.

†Total rates have been age standardised to the 1996 England population. 
Table 3 Projected numbers and age standardised rates (per 100000 ) of primary and revision joint replacement operations in 2010, with comparison with 2000. Source: HES, Department of Health

\begin{tabular}{|c|c|c|c|c|c|c|c|c|}
\hline & \multicolumn{2}{|c|}{ Primary THR } & \multicolumn{2}{|c|}{ Revision THR } & \multicolumn{2}{|c|}{ Primary TKR } & \multicolumn{2}{|c|}{ Revision TKR } \\
\hline & $\bar{N}$ & Rate & $\mathrm{N}$ & Rate & $\overline{\mathbf{N}}$ & Rate & $\bar{N}$ & Rate \\
\hline \multicolumn{9}{|c|}{2000 data } \\
\hline Men & 14521 & 65.5 & 3497 & 16.6 & 13530 & 62.2 & 1387 & 6.3 \\
\hline Women & 23904 & 87.0 & 6010 & 20.9 & 19412 & 70.7 & 1609 & 5.8 \\
\hline \multirow{2}{*}{\multicolumn{9}{|c|}{$\begin{array}{l}\text { Projected numbers and rates for } 2010 \\
\text { Method A }\end{array}$}} \\
\hline & & & & & & & & \\
\hline Men & 18903 & 73.7 & 7086 & 29.4 & 23956 & 97.0 & 3108 & 12.3 \\
\hline Women & 27869 & 94.4 & 11478 & 37.8 & 29756 & 102.1 & 3337 & 11.4 \\
\hline \multicolumn{9}{|c|}{ Method B } \\
\hline Men & 16646 & 65.5 & 4008 & 16.6 & 15384 & 62.2 & 1584 & 6.3 \\
\hline Women & 25488 & 87.0 & 6346 & 20.9 & 20510 & 70.7 & 1713 & 5.8 \\
\hline \multicolumn{9}{|c|}{ Percentage increase from 2000} \\
\hline Method & & & & & & & & \\
\hline Men & 30.2 & 12.5 & 102.6 & 77.1 & 77.1 & 55.9 & 124.1 & 95.2 \\
\hline Women & 16.6 & 8.5 & 91.0 & 80.9 & 53.3 & 44.4 & 107.4 & 96.6 \\
\hline \multicolumn{9}{|c|}{ Method B } \\
\hline Men & 14.6 & - & 14.6 & - & 13.7 & - & 14.2 & - \\
\hline Women & 6.6 & - & 6.0 & - & 5.7 & - & 6.5 & - \\
\hline
\end{tabular}

Method A involves linearly projecting the age specific trend to 2010 and applying the projected rates to the projected English population numbers for 2010. The 2010 projected rates are then age standardised to the 1996 English population.

Method B involves applying the age specific rates for the year 2000 to the projected English population numbers for 2010. The age standardised rates here are the same as those in 2000.

THR, total hip replacement; TKR, total knee replacement.

which would have detrimental effects on the functioning of patients. The effects of increased waiting time for surgery are currently unclear. Hajat and colleagues reported that increased waiting time was associated with worse preoperative function and poorer outcomes 12 months after hip surgery. ${ }^{24}$ Mahon et al also found that clinically important losses in mobility and health related quality of life occurred in patients who waited more than six months for hip replacement, but found no difference in postoperative outcomes. ${ }^{25}$ Kelly et al reported no change in pain and dysfunction among patients waiting for total hip or knee arthroplasty, ${ }^{26}$ while Nilsdotter and Lohmander found no differences in either preoperative or postoperative status between patients who waited more or less than three months for hip replacement. ${ }^{27}$ Further research is needed to fully understand the implications of delays in undergoing joint arthroplasty.

This study is unable to account for the rapid rise in revision rates over the decade. As the rates are age adjusted and the time period is relatively short, the aging of the population cannot be implicated. It may be that the trend to operate earlier in life has led to prosthetic failure at ages when revision operations can be safely done. Alternatively, Herberts and Malchau have suggested that the tendency for British surgeons in the early 1990s to adopt new techniques without proven long term results may have led to an increased need for revisions in the United Kingdom compared with Sweden. ${ }^{21}$ They attribute the greater awareness and conservatism among Swedish surgeons to the long term presence of a hip replacement register in Sweden. A Royal College of Surgeons study of hip replacement in England found that evaluated prostheses were used in only $42 \%$ of cases, ${ }^{28}$ while an investigation into the performance of the $3 \mathrm{M}$ Capital Cemented Hip System recommended that a national hip register be established. ${ }^{29}$ The ability to evaluate the outcomes and survival of different prostheses is an obvious benefit of such a register.
While this study has strength in its national coverage and long time span, it is limited by the lack of data from the private sector. The use of data from public hospitals alone provides an incomplete picture of the provision of hip and knee replacement in England. This leads to underestimation of the potential demand for surgery in the future and most probably understates the extent of the deprivation gradient. If optimal allocation of resources and delivery of equitable care is to be achieved, data on procedures undertaken in private hospitals are necessary and should be made publicly available. Further research into the need for and attitudes to surgery within the population, and investigation of possible deprivation based variation, would also assist this process. The National Joint Registry (http://www.njrcentre.org.uk) established in April 2003 will be of great value in monitoring and evaluating hip and knee replacement procedures in the United Kingdom.

\section{ACKNOWLEDGEMENTS}

This research was supported by a Medical Research Council grant. HES data were made available by the Department of Health. HES analyses conducted within the Department of Social Medicine are supported by the South West Public Health Observatory. M Shaw is supported by the South West Public Health Observatory.

\section{Authors' affiliations}

T Dixon, M Shaw, S Ebrahim, P Dieppe, Department of Social Medicine, University of Bristol, Bristol, UK

\section{REFERENCES}

1 Ling SM, Fried LP, Garrett ES, Fan MY, Rantanen T, Bathon JM. Knee osteoarthritis compromises early mobility function: the women's health and aging study II. J Rheumatol 2003;30:1 14-20.

2 Brooks PM. Impact of osteoarthritis on individuals and society: how much disability? Social consequences and health economic implications. Curr Opin Rheumatol 2002;14:573-7.

3 Reginster JY. The prevalence and burden of arthritis. Rheumatology (Oxford) 2002;41(suppl 1):3-6. 
4 McMurray A, Grant S, Griffiths S, Letford A. Health-related quality of life and health service use following total hip replacement surgery. J Adv Nurs 2002;40:663-72.

5 Walker DJ, Heslop PS, Chandler C, Pinder IM. Measured ambulation and selfreported health status following total joint replacement for the osteoarthritic knee. Rheumatology (Oxford) 2002;41:755-8.

6 Chang RW, Pellisier JM, Hazen GB. A cost-effectiveness analysis of total hip arthroplasty for osteoarthritis of the hip. JAMA 1996;20:858-65.

7 Birrell F, Johnell O, Silman A. Projecting the need for hip replacement over the next three decades: influence of changing demography and threshold for surgery. Ann Rheum Dis 1999;58:569-72.

8 Mahomed NN, Barrett JA, Katz JN, Phillips CB, Losina E, Lew RA, et al. Rates and outcomes of primary and revision total hip replacement in the United States Medicare population. J Bone Joint Surg Am 2003:85(A):27-32.

9 Hawker GA, Wright JG, Glazier RH, Coyte PC, Harvey B, Williams Jl, et al The effect of education and income on need and willingness to undergo total joint arthroplasty. Arthritis Rheum 2002;46:3331-9.

10 Chaturvedi N, Ben Shlomo Y. From the surgery to the surgeon: does deprivation influence consultation and operation rates? Br J Gen Pract 1995; 45: 127-31

11 Robertsson O, Dunbar MJ, Knutson K, Lidgren L. Past incidence and future demand for knee arthroplasty in Sweden: a report from the Swedish Knee Arthroplasty Register regarding the effect of past and future population changes on the number of arthroplasties performed. Acta Orthop Scand 2000;71:376-80

12 Robertsson O, Knutson K, Lewold S, Lidgren L. The Swedish Knee Arthroplasty Register 1975-1997: an update with special emphasis on 41,223 knees operated on in 1988-1997. Acta Orthop Scand 2001;72:503-13.

13 Lucht U. The Danish Hip Arthroplasty Register. Acta Orthop Scand 2000;71:433-9.

14 Havelin LI, Engesaeter LB, Espehaug B, Furnes O, Lie SA, Vollset SE. The Norwegian Arthroplasty Register: 11 years and 73,000 arthroplasties. Acto Orthop Scand 2000;71:337-53.

15 Puolakka TJ, Pajamaki KJ, Halonen PJ, Pulkkinen PO, Paavolainen P, Nevalainen JK. The Finnish Arthroplasty Register: report of the hip register. Acta Orthop Scand 2001;72:433-41.
16 Wells VM, Hearn TC, McCaul KA, Anderton SM, Wigg AE, Graves SE. Changing incidence of primary total hip arthroplasty and total knee arthroplasty for primary osteoarthritis. J Arthroplasty 2002; 17:267-73.

17 American Academy of Orthopaedic Surgeons. Orthopaedic-related Statistics. http://www.aaos.org/wordhtml/research/stats/stats 3.htm accessed 16-5-2003.

18 Williams B, Whatmough P, McGill J, Rushton L. Private funding of elective hospital treatment in England and Wales, 1977-8. BMJ 2003;320:904-5

19 Townsend P, Philmore P, Beattie A. Health and deprivation: inequality and the North. London: Croom Helm, 1988.

20 Department of Health. Hospital Episode Statistics, 2000/01. http:// www.doh.gov.uk/hes/free_data/index.html accessed 16-5-2003.

21 Herberts $\mathbf{P}$, Malchau H. Long-term registration has improved the quality of hip replacement: a review of the Swedish THR Register comparing 160,000 cases. Acta Orthop Scand 2000;71:111-21.

22 Department of Health. Reducing health inequalities: an action report. London: Department of Health, 1999.

23 Department of Health. Reference costs 2002. London: Department of Health, 2002.

24 Hajat S, Fitzpatrick R, Morris R, Reeves B, Rigge M, Williams O, et al. Does waiting for total hip replacement matter? Prospective cohort study. J Health Serv Res Policy 2002;7:19-25.

25 Mahon JL, Bourne RB, Rorabeck CH, Feeny DH, Stitt L, Webster-Bogaert S. Health-related quality of life and mobility of patients awaiting elective total hip arthroplasty: a prospective study. CMAJ 2002;167:11115-21.

26 Kelly KD, Voaklander DC, Johnston DWC, Newman SC, Suarez-Almazor ME. Change in pain and function while waiting for major joint arthroplasty. J Arthroplasty 2001;16:351-9.

27 Nilsdotter AK, Lohmander LS. Age and waiting time as predictors of outcome after total hip replacement for osteoarthritis. Rheumatology 2002;41:1261-7.

28 The Royal College of Surgeons of England and the British Orthopaedic Association. National Total Hip Replacement Outcome Study: Final report to the Department of Health. London: The Royal College of Surgeons of England, 2000.

29 RCS. An investigation of the performance of the 3M Capital Hip System. London: The Royal College of Surgeons of England, 2001. 